\title{
Correspondence
}

\section{Genito-urinary medicine}

TO THE EDITOR, British fournal of Venereal Diseases

SIR-There seems to be some difference of opinion concerning the name of the specialty incorporating venereology and the study of sexually transmitted diseases (see, for instance, Correspondence in the Brit. med. F. (1975) 1, 332). Many of those working in this specialty are aware of the need to recognize the wide implications of their work. Many specialties in the past, when separating from the main stem of Medicine or Surgery, acquired their specialist dimension only after a period of time.

Genito-urinary medicine has been somewhat poorly served in the past by physicians; it concerns an area of the body which until recently was given only cursory attention in the medical schools. Many disorders in the area of the lower genito-urinary tract have until now been dealt with solely by surgical specialists. The Surgeons have many distinguished and indipensable qualities, but they are primarily therapists who concentrate on the correction of lesions. This limits the usefulness of their work for the 'whole man'. Lower genitourinary tract disorders may be diseases of body and mind as much as those arising in any other area; they need the same attitude and expertise from the physician. Genito-

\section{Single dose penicillin therapy}

\section{TO THE EDITOR, British fournal of Venereal Diseases}

SIR-It has been suggested that single dose penicillin therapy as used for the treatment of gonorrhoea is likely to suppress or cure incubating syphilis (Woodcock, K. R. (1974) Brit. F. vener. Dis., 47, 95). We have recently seen a case in this department in which a man treated for a rectal gonococcal infection with $5 \mathrm{~m}$.u. benzyl penicillin and $1 \mathrm{~g}$. probenecid was found to have anal primary syphilis 3 weeks later.

A 38-year-old Caucasian homosexual had been attending regularly since he was treated for secondary syphilis in December, 1970. Since that time he had remained well apart from two rectal gonococcal infections, in 1969 and 1972. His reagin tests (WR, later RPR) had been negative since 1971. His TPHA had been positive since the test was introduced into this department in early 1974.

When he was seen on February 13, 1975, the RPR was negative and TPHA positive. He attended again on February 21 with anal discomfort, and admitted a casual urinary medicine fulfils this need, for the genito-urinary physician is brought face to face with the manifold problems that arise from life and its relationships, and with the great variety of diseases that affect this area of the body. For the patients' sake, the dominant suggestion of 'sex' must be removed from the title of the specialty, in the same way as it is absent from urology and gynaecology. 'Sexually Transmitted Diseases' equates with 'Venereal', the name describes an important part of this branch of medicine, and in the past and to some extent now it has carried the suggestion of 'behaviour problems'.

No specialty entirely limited to the study of an infection and its treatment will survive in the long run, as can be seen from the specialties of 'infectious diseases' and 'tuberculosis'. Anyone wishing to devote his whole interest to genito-urinary infections should remain an epidemiologist or microbiologist. Today society requires more than this from a physician managing patients who present with the many disorders which arise in the first instance in the lower genito-urinary tract.

Yours faithfully,

A. S. GRIMBLE

GuY's Hospital

LoNDON SE1 9RT

May 61975 passive relationship 4 weeks previously; he was found to have gonococcal proctitis, and was treated with 5 m.u. benzyl-penicillin intramusculárly with $1 \mathrm{~g}$. probenecid by mouth. When he returned on March 6 a small anal sore was noted; dark-ground examination of material from the sore was negative for $T$. pallidum, but the serology now showed an RPR titre of 1:64. He returned on March 14, when dark-ground examination was repeated and $T$. pallidum was demonstrated. He was treated with a course of twelve doses of $600,000 \mathrm{u}$. procaine penicillin.

The patient firmly denied any sexual activity since the casual contact at the end of January; unfortunately it proved impossible to locate this contact. In this patient it seems probable that a large dose of penicillin given during the incubation period of his syphilitic infection was not sufficient to suppress it. Yours faithfully,

J. T. WRIGHT

Department of Genito-URinary Medicine

UNIVERSITY CoLLEGE HosPITAL

London WC1E 6AU

April 17, 1975 